\title{
Impact of Chromosomal Heteromorphisms on Recurrent Miscarriages
}

\author{
Sandesh Chopade ${ }^{1 *}$, Chopade DK ${ }^{2}$ and Harish Harde ${ }^{2}$
}

${ }^{1}$ Department of Bioengineering, IIT, Kanpur, India

${ }^{2}$ Genetic Health \& Research Center, 7, Mahatmanagar, Nashik, Maharashtra, India

\begin{abstract}
Introduction: Chromosomal Heteromorphisms are the inherited variations at specific chromosomal regions without a proven impact on the phenotype of an individual.

Material and Methods: We studied and compared the chromosome Heteromorphisms in the Karyotypes of two groups. The first group consisted of 320 individuals of 160 couples with more than two miscarriages and no live birth and the second group consisted of 412 individuals of 206 normal couples with more than 1 normal child birth.

Results and discussion: Twenty Nine individuals (9.06\%) with a history of recurrent pregnancy loss were found to have chromosomal heteromorphisms, whereas thirteen individuals $(3.1 \%)$ from the normal group were having the chromosomal heteromorphism. The difference between the two groups was statistically significant $(p<0.0001)$

Conclusion: These results are consistent with other similar studies that suggest the yet undefined relationship between chromosome heteromorphism and recurrent pregnancy loss.
\end{abstract}

Keywords: Recurrent pregnancyloss; Chromosomeheteromorphism

\section{Introduction}

Repeated DNA sequences in the genome are subject to heteromorphism [1]. Chromosomal heteromorphisms are structural chromosomal variants that are widespread in human populations and have no known effect on phenotype [2]. These heteromorphic regions may be identified by several methods; each of these methods reveals a typical staining pattern implying constitutional differences in heterochromatin. Common chromosomal polymorphisms detected by Giemsa banding are considered as heteromorphisms and include heterochromatin regions on short arms of Acrocentric chromosomes and regions of chromosomes 1, 9, 16 and Y. Impact of chromosome heteromorphism has been studied previously on infertility and recurrent miscarriages $[1,3]$. There seems an increased incidence of chromosome heteromorphism in infertility and recurrent miscarriages; however, the underlined mechanism needs to be clearly defined yet.

We aimed to study the impact of chromosomal heteromorphisms of Acrocentric chromosomes on recurrent miscarriages in the present study, by comparing the frequencies of heteromorphic regions in Karyotypes of normal individuals and the couples with recurrent pregnancy losses.

\section{Material and Methods}

We studied and compared the chromosome Heteromorphisms in the Karyotypes of two groups. The first group consisted of 160 couples with more than two first trimester miscarriages and no live birth that were referred to our Genetic Health \& Research Center between October 2010 to December 2011 for Karyotyping and the second group consisted of 412 individuals of 206 normal couples with more than 1 normal child births and absence of history of abortions.

Chromosomal analysis was done in cytogenetic laboratory using standard methods. Peripheral blood samples from individuals of both the groups were cultured for 72 hours and chromosomes were studied after Giemsa- Trypsin banding.

At least 20 metaphases were analysed for each case and heteromorphisms were reported according to ISCN 2005.
Prominent stalks and satellites of chromosomes 13, 14, 15, 21 and 22 were included in the study. The findings were considered heteromorphic if the chromosome region of interest was greater than the same region of its homologue.

All the detected heteromorphic Karyotypes were examined under light microscope by two independent laboratory technicians in the laboratory to avoid uncertainty and variability in the results.

Statistical analysis was done by two- tailed Fisher's exact test.

\section{Results and Discussion}

In couples with recurrent pregnancy loss, twenty nine individuals (16 males and 13 females; 9.06\%) were found to have chromosomal heteromorphisms in the acrocentric chromosomes. In males the frequency of heteromorphism was $10 \%$ and in the females $8.12 \%$ (Table 1).

Most of the spontaneous miscarriages occur because of chromosomal abnormalities in the embryo or foetus [4-6]. Several early studies [5,7-10] suggested that the variation in size of heterochromatic regions on human chromosome might have deleterious effect. Hong Y et al. [11] has shown that the outcome of infertility treatment (IVF/ ICSI) in non-carriers and carriers of polymorphic chromosome variants does not differ; however, the early miscarriage rate of the male carriers tends to be higher.

The chromosomal polymorphisms of short arms of acrocentric chromosomes have been reported in humans by Podugolnikova et

*Corresponding author: Sandesh Chopade, Department of Bioengineering, IIT, Kanpur, India, E-mail: drchopade@hotmail.com

Received April 15, 2012; Accepted July 11, 2012; Published July 11, 2012

Citation: Chopade S, Chopade DK, Harde H (2012) Impact of Chromosomal Heteromorphisms on Recurrent Miscarriages. Human Genet Embryol 1:101. doi:10.4172/2161-0436.1000101

Copyright: (c) 2012 Chopade S, et al. This is an open-access article distributed under the terms of the Creative Commons Attribution License, which permits unrestricted use, distribution, and reproduction in any medium, provided the original author and source are credited. 
Citation: Chopade S, Chopade DK, Harde H (2012) Impact of Chromosomal Heteromorphisms on Recurrent Miscarriages. Human Genet Embryol 1:101. doi:10.4172/2161-0436.1000101

Page 2 of 2

\begin{tabular}{|c|c|c|c|c|c|c|}
\hline \multirow{2}{*}{$\begin{array}{c}\text { Chromo- } \\
\text { somes }\end{array}$} & \multicolumn{2}{|c|}{$\begin{array}{c}\text { Number of heteromorphic } \\
\text { chromosomes in Group I (320) }\end{array}$} & \multicolumn{3}{c|}{$\begin{array}{c}\text { Number of heteromorphic } \\
\text { chromosomes in Group II (412) }\end{array}$} \\
\cline { 2 - 3 } & Male (16) & Female (13) & Total & Male (6) & Female (7) & Total \\
\hline 13 & 2 & 2 & 29 & 1 & 1 & \multirow{2}{*}{$13(3.1 \%)$} \\
\hline 14 & 2 & 2 & \multirow{2}{*}{$(9.06 \%)$} & 0 & 1 & \\
\cline { 1 - 3 } & 7 & 5 & & 2 & 3 & \\
\hline 21 & 1 & 1 & & 1 & 1 \\
\hline 22 & 4 & 3 & & 2 & 1 & \\
\hline
\end{tabular}

Group I- Couples with more than 2 first trimester miscarriages and no live birth Group II- Couples with more than 1 normal child and absence of history of abortions

Table 1: Acrocentric Chromosomal heteromorphism observed in two groups.

al. [12]. According to the present study, the most frequently affected chromosomes are chromosome 15 and 22 as compared to chromosomes 13,14 and 21, which is consistent with the findings of Purandare et al. [3]. No specific functions have been reported to be associated with the satellite segments (ps+); however, such variations in the couple may make the fetus susceptible to translocations which may lead to fetal wastage [3]. Karyotyping 842 individuals with primary infertility or repeated miscarriages by Madon et al. [10] showed polymorphic variants in $28.82 \%$ of males and $17.19 \%$ of females, which was quite high as compared to $10 \%$ males and $8.12 \%$ of females in our study. The present research finding shows that the incidence of heterochromatic variations on the short arms of acrocentric chromosomes is higher in couples with early miscarriages.

\section{Conclusion}

Present study shows that the prevalence of acrocentric chromosomal heteromorphisms is higher in coupes with early miscarriages and is consistent with figures described in several populations across the world. This could be an important reason for early miscarriage. However; the number of carriers of acrocentric chromosomal variations in our study was insufficient. Moreover, the chromosomal analysis method in the present study had 450 Giemsa banding resolution. Therefore, to establish a definite relationship, more sample size and more sensitive techniques are needed.

\section{References}

1. Sahin FI, Yilmaz Z, Yuregir OO, Bulakbasi T, Ozer O, et al. (2008) Chromosome heteromorphisms: an impact on infertility. J Assist Reprod Genet 25: 191-195.

2. Milunsky A, Milunsky J (2011) Genetic Disorders and the Fetus: Diagnosis, Prevention and Treatment. (6th edn) John Wiley \& Sons, New York.

3. Purandare H, Fernandez NV, Deshmukh SV, Chavan S (2011) Heterochromatic variations and Pregnancy losses in Humans. Int J Hum Genet 11: 167-175.

4. Rimoni DL, Connor JM, Reed EP (2002) Emery and Rimoin's Principles and Practice of Medical Genetics. (3 rdedn), Churchil Livingstone, Edinburg.

5. Bhasin MK (2005) Human Population Cytogenetics: A Review. Int J Human Genetics 5: 83-152.

6. Korteweg FJ, Bouman K, Erwich JJ, Timmer A, Veeger NJ, et al. (2008) Cytogenetic analysis after evaluation of 750 fetal deaths: proposal for diagnostic workup. Obst Gyneacol 111: 865-874

7. Lubs HA, Kinberling WJ, Hecht F, Patil SR, Brown J, et al. (1977) Racia differences in the frequency of $Q$ and $C$ chromosomal heteromorphisms. Nature 268: 631-633.

8. Hook EB, IH Porter (Eds) Population cytogenetics: studies in humans: proceedings of a Symposium on Human Population Cytogenetics sponsored by the Birth Defects Institute of the New York State Department of Health, held in Albany, New York, October 14-15, 1975. Academic Press, New York.

9. Say B, Carpenter NJ, Lanier PR (1977) Chromosome variations in children with psychiatric disorders. Am J Psychiatry 134: 424-426.

10. Madon PF, Athalye AS, Parikh FR (2005) Polymorphic variants on chromosomes probably play a significant role in infertility. Reprod Biomed Online 11: 726-732.

11. Hong Y, Zhou YW, Tao J, Wang SX, Zhao XM (2011) Do polymorphic variants of chromosomes affect the outcomes of in vitro fertilization and embryo transfer treatment? Human Reprod 26: 933-940.

12. Podugol'nikova OA, Bliumina MG (1982) Heterochromatic regions of chromosomes 1, 9, 16 and $\mathrm{Y}$ in children with signs of embryonic development disorder. Genetika 18: 2052-2054. 